\title{
A case study of the effect of grain size on the oxygen permeation flux of BSCF disk-shaped membrane fabricated by thermoplastic processing
}

\author{
Mehdi Salehi ${ }^{\mathrm{a}, \mathrm{b}, *}$, Frank Clemens ${ }^{\mathrm{a}}$, Ewald M. Pfaff ${ }^{\mathrm{c}}$, Stefan Diethelm $^{\mathrm{d}}$, Colin Leach $^{\mathrm{e}}$, \\ Thomas Graule ${ }^{\mathrm{a}}$, Bernard Grobéty ${ }^{\mathrm{b}}$ \\ a Laboratory for High Performance Ceramics, Empa, Swiss Federal Laboratories for Materials Science and Technology, Ueberlandstrasse 129, CH-8600 Duebendorf, Switzerland \\ ${ }^{\mathrm{b}}$ The Fribourg Center for Nanomaterials (FriMat) and Department of Geosciences, University of Fribourg, Pérolles Ch. du Musée 6, CH-1700 Fribourg, Switzerland \\ c Institute for Materials Applications in Mechanical Engineering, RWTH Aachen University, Nizzaallee 32, 52072 Aachen, Germany \\ ${ }^{d}$ Laboratory for Industrial Energy Systems (LENI), STI, Swiss Federal Institute of Technology, 1015 Lausanne, Switzerland \\ e School of Materials, The University of Manchester, Manchester M13 9PL, United Kingdom
}

\section{Introduction}

Perovskite-based, mixed ionic-electronic conductors (MIEC) are of great interest because of their $100 \%$ oxygen permselectivity at elevated temperatures. These materials are widely under development as ceramic membranes for oxygen separation and in catalytic partial oxidation reactors, as electrodes for solid oxide fuel cells and for high temperature electrolysis [1-4]. Oxygen permeation in MIEC membranes is driven solely by a difference of oxygen partial pressure (oxygen potential gradient) on either side of the membranes.

Since Teraoka reported high oxygen permeation flux in $\mathrm{La}_{1-x} \mathrm{Sr}_{x} \mathrm{Co}_{1-y} \mathrm{Fe}_{y} \mathrm{O}_{3-\delta}$ (LSCF) ceramic membranes in the late 1980s [5,6], a large number of studies have been carried out to optimize oxygen permeation in this system, with $\mathrm{SrCO}_{0.8} \mathrm{Fe}_{0.2} \mathrm{O}_{3-\delta}$ (SCF) showing significant promise. However, later studies revealed that the SCF phase was not stable below $800^{\circ} \mathrm{C}$ at oxygen partial

\footnotetext{
* Corresponding author at: Laboratory for High Performance Ceramics, Empa, Swiss Federal Laboratories for Materials Science and Technology, Ueberlandstrasse 129, CH-8600 Duebendorf, Switzerland. Tel.: +4158 765 4952; fax: +41 448234150. E-mail addresses: Mehdi.Salehi@empa.ch, chemehdi3333@gmail.com (M. Salehi), Frank.Clemens@empa.ch (F. Clemens).
}

pressures lower than about 0.1 atm due to oxygen vacancy ordering [5,7-10].

It was later found that the structural and chemical stability of the SCF membranes were greatly improved by partial substitution of $\mathrm{Sr}$ with $\mathrm{Ba}$, retaining a high oxygen permeation flux for compositions around $\mathrm{Ba}_{0.5} \mathrm{Sr}_{0.5} \mathrm{Co}_{0.8} \mathrm{Fe}_{0.2} \mathrm{O}_{3-\delta}$ (BSCF). Recently, $\mathrm{BSCF}$ has received increasing attention for use in ceramic oxygen membranes [11-15].

It has been reported that the oxygen permeation flux of the MIEC membranes is sensitive to microstructural features, such as grain size and grain boundary structure [16-26]. The microstructure depends both on processing history, and especially the sintering procedure, even for similar components. The preparation of MIEC membranes can be considered in terms of three steps: (1) powder synthesis, (2) shaping, and (3) sintering. The influence of each of these steps on the microstructure and oxygen permeation flux of the MIEC membranes has been investigated over the last decade, with several different behaviors reported [13,16,17,19-21,24].

In the case of BSCF, previous studies have resulted in conflicting data, especially with regard to the influence of grain size on permeation $[13,14,18,22-26]$. The effect of the microstructural on the oxygen permeation flux cannot be generalized and the contradictions could be attributed to microstructural variations caused by differences in powder synthesis routes and sintering conditions used by different groups. 
BSCF powder thermoplastic binder surfactant

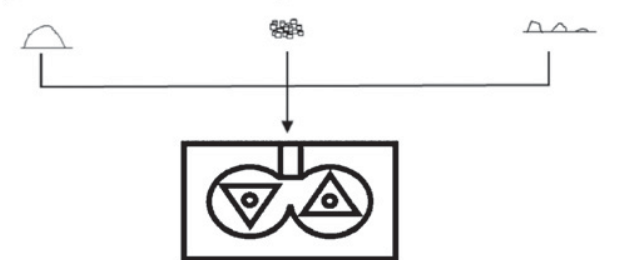

High Shear Mixer

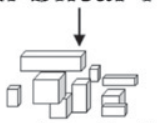

Thermoplastic feedstock
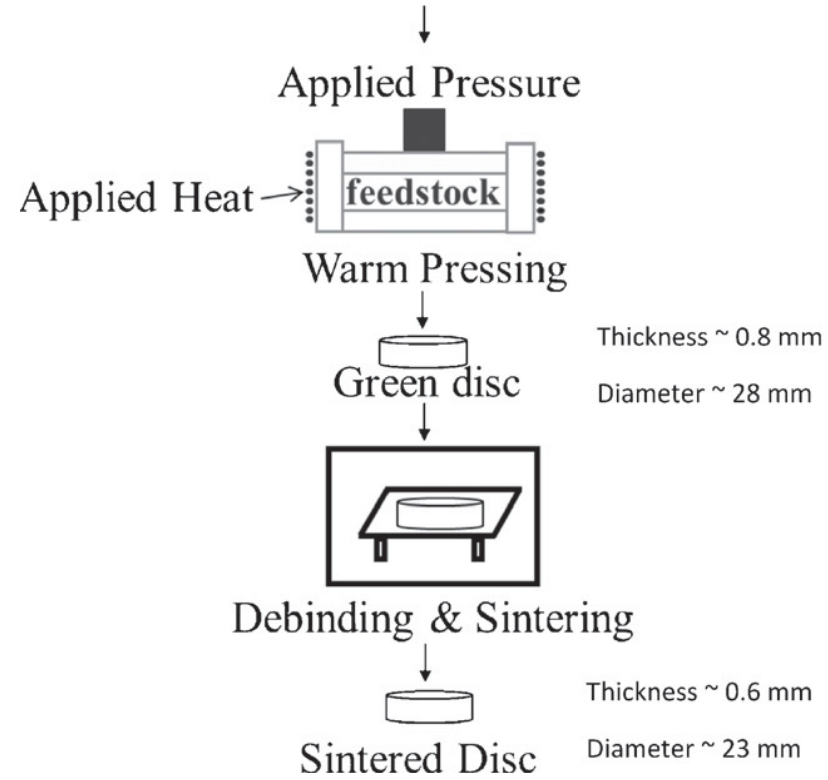

Fig. 1. Schematic diagram of the BSCF membrane fabrication.

In this study, we have examined the effect of grain size on the oxygen permeation flux of $\mathrm{Ba}_{0.5} \mathrm{Sr}_{0.5} \mathrm{Co}_{0.8} \mathrm{Fe}_{0.2} \mathrm{O}_{3-\delta}$ membranes, fabricated by warm pressing. Three samples with differing grain sizes were prepared by sintering at different temperatures. The associated microstructural changes were characterized using scanning electron microscopy (SEM) combined with electron backscatter diffraction (EBSD) for texture analysis and conductive mode (CM) microscopy to observe the local electrical behavior in the BSCF membrane. Oxygen permeation experiments were also carried out on the membranes sintered at each temperature.

\section{Experimental}

\subsection{Sample preparation}

Commercially available $\mathrm{Ba}_{0.5} \mathrm{Sr}_{0.5} \mathrm{Co}_{0.8} \mathrm{Fe}_{0.2} \mathrm{O}_{3-\delta}$ (BSCF) powder (Treibacher, Austria), with a mean particle size of $3 \mu \mathrm{m}$ and a specific surface area of $1.55 \mathrm{~m}^{2} / \mathrm{g}$ was used. Mean particle size $\left(d_{\mathrm{BET}}\right)$ also was calculated from the BET according to $d_{\mathrm{BET}}=6 /\left[\rho_{\mathrm{th}} S_{\mathrm{BET}}\right]$, where $\rho_{\text {th }}$ is the theoretical density of the BSCF powder measured by He-pycnometer and $S_{\mathrm{BET}}$ is the measured surface area by BET and a value of $0.70 \mu \mathrm{m}$ was determined.

Fig. 1 shows the thermoplastic processing route used for fabricating the disk shaped membranes. Polystyrene (type 648, Dow Company, Switzerland) and polyethylene glycol (PEG 20000)(Fluka AG, Switzerland) were added as binders, with additions of stearic acid as a surfactant (Fluka AG, Switzerland) in the preparation of the feedstock, forming a ceramic-polymer composite with $48 \%$ volume fraction of polymer. This is in agreement with literature reports that the usual powder content attained is around 52 vol.\% for ceramic feedstock with binders based on thermoplastic polymers [27]. The feedstock was prepared using a high shear mixer (HAAKE PolyLab Mixer, Rheomix 600, Thermo Scientific, Germany). The mixing was carried out using a two step sequence: in the first step, the mixing was performed at $10 \mathrm{rpm}$ and $170^{\circ} \mathrm{C}$ for $30 \mathrm{~min}$ and subsequently at $10 \mathrm{rpm}$ and $150^{\circ} \mathrm{C}$ for $150 \mathrm{~min}$ until the mixing torque reached a constant value.

The feedstocks were loaded into a steel die with heating mantle and uniaxially pressed at $30 \mathrm{kN}$ and $165^{\circ} \mathrm{C}$ for $30 \mathrm{~min}$ to form disk-shaped membranes, approximately $28 \mathrm{~mm}$ in diameter. The elimination of the binder was achieved by thermal debinding, employing a slow heating rate up to $600^{\circ} \mathrm{C}$ in air. To provide samples with different grain size, sintering was carried out at $1000^{\circ} \mathrm{C}$, $1050^{\circ} \mathrm{C}$ and $1100^{\circ} \mathrm{C}$ for $2 \mathrm{~h}$, using a heating rate of $1^{\circ} \mathrm{C} / \mathrm{min}$. The densities of the sintered samples were measured by the Archimedes method. The porosity of the sintered disks was determined using image analysis (Digital Micrograph 3.10.0, Gatan Inc.). Additionally the porosity was calculated by the quotient of the Archimedes density and the skeleton density (He-pycnometer) and subtracting the results from one.

\subsection{Basic characterization}

\subsubsection{Electron Backscattered Diffraction (EBSD)}

EBSD is widely used in quantitative metallography; particularly for subgrain imaging and texture determination [28-30]. Its use in ceramics research is increasing but is limited by difficulties in producing the necessary strain-free surface to allow channeling of electrons to take place. A further benefit is that orientation contrast allows grains to be differentiated easily without sample etching.

Kikuchi-type diffraction patterns, generated by backscattered electrons [28-30], are recorded for each point of analysis. The crystallographic orientation is determined after indexing of the corresponding diffraction pattern. The structure factors of the reflectors are calculated with Electron Microscopy Image Simulation (EMS) software developed by Stadelmann [31]. For the EBSD sample preparation, the sintered samples were ground and polished to achieve a smooth strain-free surface. All EBSD data were collected at the University of Fribourg using a Philips ${ }^{\circledR}$ FEI XL30 SFEG Sirion SEM equipped with an EDAX ${ }^{\circledR}$ (TSL) OIM 3.5 software package. The best results were obtained with an accelerating voltage of $15 \mathrm{kV}$ and a probe current of $20 \mathrm{nA}$. The sample tilt was $70^{\circ}$ and working distance of $15 \mathrm{~mm}$. To reduce the measuring time, the resolution, i.e. the step size and analyzed area were adjusted to match the average grain size. For the fine grained material sintered at $1000^{\circ} \mathrm{C}$ an area of $120 \mu \mathrm{m} \times 120 \mu \mathrm{m}$ was mapped with a step size of $0.25 \mu \mathrm{m} / \mathrm{step}$, whereas for coarse grained membrane sintered at $1100^{\circ} \mathrm{C}$ an area of $570 \mu \mathrm{m} \times 264 \mu \mathrm{m}$ was mapped at a resolution of $1.25 \mu \mathrm{m} / \mathrm{step}$.

Orientation distribution functions were calculated for the (1 00 ), (1 01 ) and (11 1 ) axes. To estimate the strength of the Lattice Preferred Orientation (LPO), the texture index $J$, which is the mean square value of the orientation distribution function, was determined [32]. A purely random LPO gives $J=1.0$, with $J$ increasing with the degree of preferred orientation. For a single crystal, $J$ tends to infinity (in practice it is limited to about 270 due to the truncation in the spherical harmonics calculations).

The grain misorientation distribution has been determined from the ODF (Orientation Distribution Function) and compared to random distributions [33]. The grain boundaries (GB's) satisfying the coincidence site lattice (CSL) model for the multiplicity index $\Sigma$ values up to 49 were automatically detected for cubic materials, using the list integrated in the software [34]. The multiplicity index $\Sigma$ is 


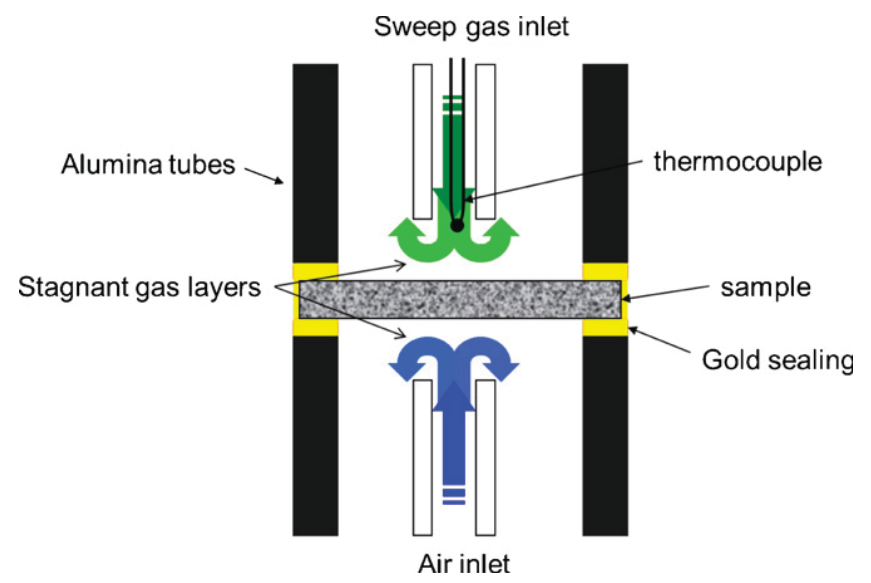

Fig. 2. Schematic picture of setup of the measurement device for oxygen permeation flux of membranes [35].

defined as the reciprocal ratio between the total number of sites and the number of coincident sites of two interpenetrating lattices. The latter form the coincident site lattice. The smaller the $\Sigma$ value the higher the coincidence between both lattices. The boundaries separating neighboring grains, for which the interpenetrating lattices form a CSL with low $\Sigma$ index, are often parallel to planes of the latter. Special GB's corresponding to given $\Sigma$ values were counted and expressed as a fraction of the total GB's. The number and type of such special boundaries determined in the present samples have been compared with the values calculated for a random microstructure.

\subsubsection{Permeation measurements}

The set-up used for permeation experiments is shown in Fig. 2. Measurements were carried out as has been described previously [35]. The sintered disc membranes, approximately $23 \mathrm{~mm}$ in diameter and $0.6 \mathrm{~mm}$ in thickness, were clamped between two alumina tubes and sealed using gold rings and paste. The surface of the samples was ground before permeation measurement. Synthetic air (350 Nml/min) was pumped into the lower compartment, and argon $(99.999 \%)(100 \mathrm{Nml} / \mathrm{min})$ was used as sweep gas in the upper one. Oxygen was separated from air by solid state diffusion through the dense membrane due to the oxygen partial pressure gradient and released on the argon side. The outlet gas composition was analyzed with a gas chromatograph (GC) (Varian Inc.) equipped with a molecular sieve, $5 \AA$ capillary columns and a TCD detector. The outlet flux was measured using a digital flow-meter (Varian Inc.). Any leakage could be detected from the presence of $\mathrm{N}_{2}$ in the outlet gas. The sample was first heated up to $1000^{\circ} \mathrm{C}$ to soften the gold rings and ensure a good seal. The temperature was then decreased step-wise, with permeation measurements made every $25^{\circ} \mathrm{C}$. The flux was measured after equilibration of the sample. Flux measurements were repeated up to 7 times for each condition to check the reproducibility.

\subsubsection{Conductive mode (CM) microscopy}

The conductive mode (CM) of the SEM uses currents flowing in the sample under beam irradiation as the image forming signal [36] and is used in the characterization of semiconductors and some electroceramics [37-41]. In use, two current collecting electrodes are positioned on the sample surface to either side of the area of interest, permitting currents that are generated within the sample as a result of primary electron beam bombardment to be collected and amplified to form the image (Fig. 3).

CM microscopy has been used to observe local resistivity variations in electroceramics using resistive contrast (RC) imaging techniques $[37,40,41]$. In this mode of operation a pair of electrodes is deposited on either side of the area of interest, making electrical contact. One electrode is connected directly to earth and the other connected to an amplifier so that the absorbed beam current flowing through it can be used to control the brightness of the RC image on the screen. As the electron beam scans the area between the electrodes, injecting current, the sample acts as a current divider and varies the proportion of current flowing to each electrode (Fig. 3). In a uniformly resistive specimen the current flowing to the amplifier and hence the screen brightness varies smoothly. However, a local change in specimen resistivity changes the rate of variation of current reaching the amplifier, and is seen as a perturbation in the brightness gradient in the RC image. The resolution of the technique is limited by the size of the electron excitation volume in the specimen, and is therefore dependent on beam energy and specimen density, and in the case of our material and experimental conditions is approximately $1.1 \mu \mathrm{m}$. To observe RC in our sample, pairs of $100 \mu \mathrm{m}$ square, gold electrodes, separated by $50 \mu \mathrm{m}$ were applied to a polished face of the BSCF sample through a photolithography-applied mask. The samples were mounted on an electrically insulating sample holder in a JEOL 6300 SEM, and connected to the amplifier via tungsten probes controlled by a micromanipulator. The $\mathrm{CM}$ signal collected under primary beam irradiation (10 keV, $5 \mathrm{nA}$ ) was amplified for imaging and linescan analysis using a commercial EBIC amplifier (Gatan EbiQuant).

\section{Results}

Table 1 gives the sintered density, average grain size and porosity of the BSCF membranes sintered at different temperatures. The sintered densities and grain size both increase with increasing sintering temperature.

Fig. 4 shows Secondary Electron (SE) images of the membrane samples sintered at each temperature, with superimposed

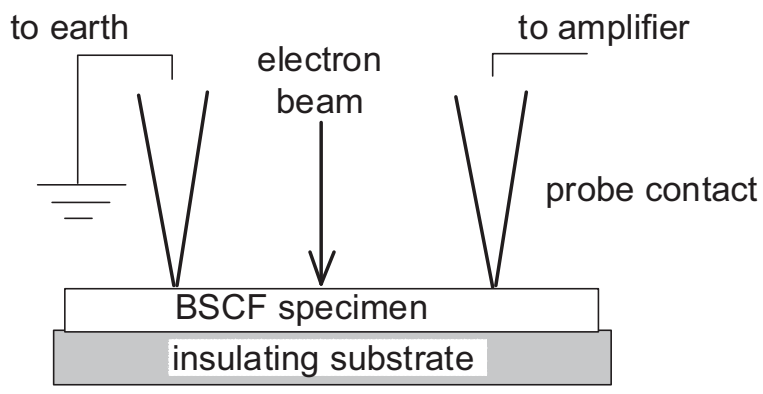

Fig. 3. CM configuration. 
Table 1

Effect of the sintering temperature on the densification of the membrane.

\begin{tabular}{lllll}
\hline $\begin{array}{l}\text { Sintering } \\
\text { temperature } \\
\left({ }^{\circ} \mathrm{C}\right)\end{array}$ & $\begin{array}{l}\text { Sintered } \\
\text { density }^{\mathrm{b}} \\
\left(\mathrm{g} / \mathrm{cm}^{3}\right)\end{array}$ & $\begin{array}{l}\text { Sintered } \\
\text { density } \\
\text { theoretical })\end{array}$ & $\begin{array}{l}\text { Porosity } \\
(\%)\end{array}$ & $\begin{array}{l}\text { Average grain } \\
\text { size }^{\mathrm{c}}(\mu \mathrm{m})\end{array}$ \\
\hline 1000 & $5.29 \pm 0.02$ & $96.27 \pm 0.36$ & $3.45 \pm 0.46$ & 3.32 \\
1050 & $5.32 \pm 0.02$ & $96.63 \pm 0.15$ & $3.25 \pm 0.28$ & 6.86 \\
1100 & $5.38 \pm 0.01$ & $97.91 \pm 0.25$ & $1.82 \pm 0.42$ & 18.25 \\
\hline
\end{tabular}

a Porosity was determined from measured density (Archimedes method) and skeleton density (pycnometer).

b The average and deviation values were reported for three samples at each sintering temperature.

c Average grain size was determined from the EBSD analysis.

EBSD orientation maps, in which each grain's crystallographic orientation relative to the image normal is given by the color in the unit triangle. (For interpretation of the references to color in this sentence, the reader is referred to the web version of the article.) Grain size distribution of samples was determined by $d_{10} \approx 2 \mu \mathrm{m}$ and $d_{90} \approx 7 \mu \mathrm{m}$ after sintering at $1000^{\circ} \mathrm{C} / 2 \mathrm{~h}, d_{10} \approx 6 \mu \mathrm{m}$ and $d_{90} \approx 17 \mu \mathrm{m}$ after sintering at $1050^{\circ} \mathrm{C} / 2 \mathrm{~h}$, as well as $d_{10} \approx 12$ and $d_{90} \approx 40$ for the sample sintered at $1100^{\circ} \mathrm{C} / 2 \mathrm{~h}$. The black areas in the SE image, which are not indexed in the EBSD orientation maps, correspond to pores, which are $1-10 \mu \mathrm{m}$ in diameter and are located both within the grains and at the grain boundaries. The proportion of intra-granular pores increases with increasing sintering temperature. The overall porosity (determined by image analysis) was about $11.8 \%, 8.8 \%$ and $6.1 \%$ for the membranes sintered

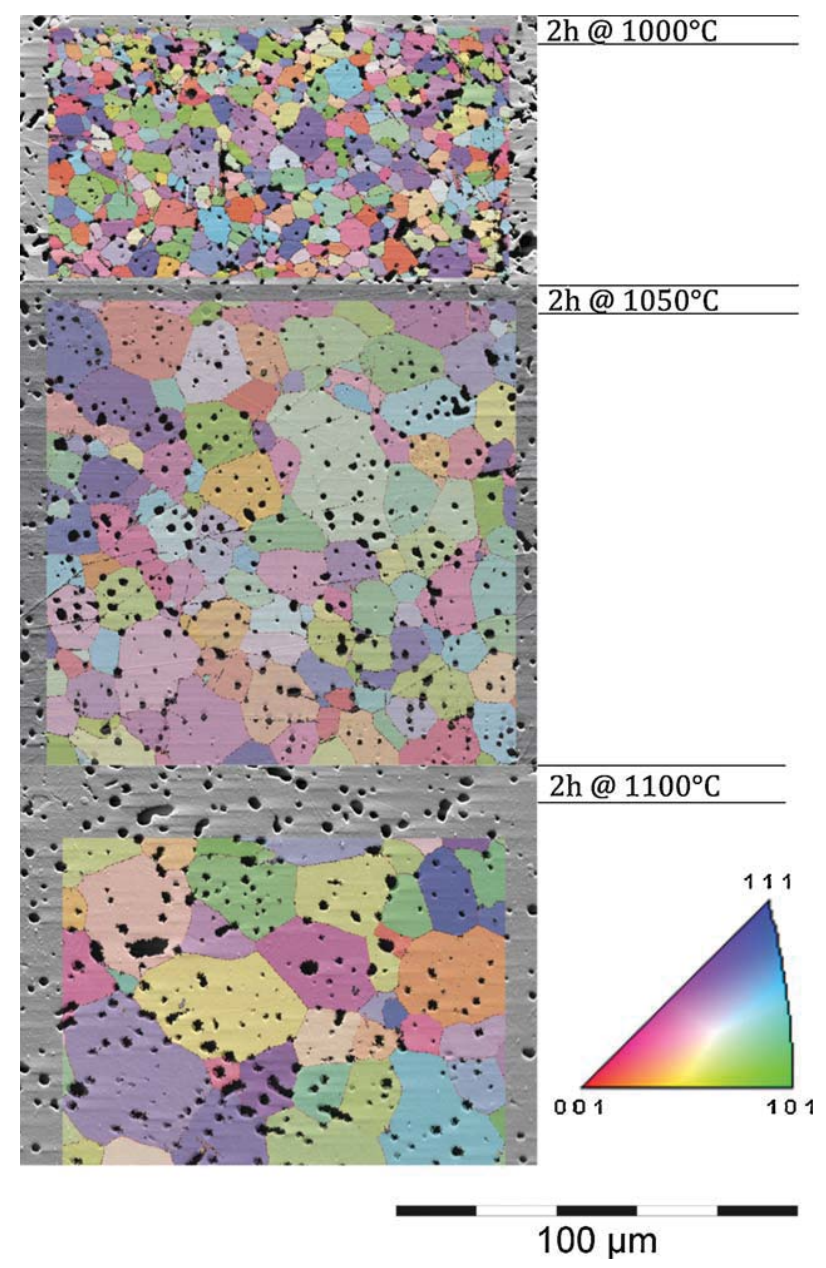

Fig. 4. SE images with superimposed grain orientation maps of cross-sections of the membranes sintered at: (a) $1000^{\circ} \mathrm{C}$, (b) $1050^{\circ} \mathrm{C}$, and (c) $1100^{\circ} \mathrm{C}$.

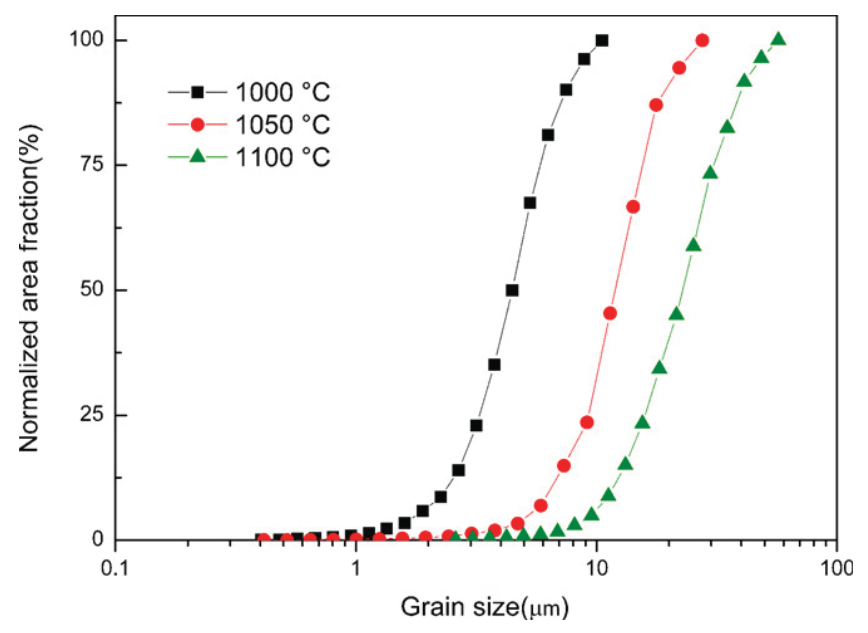

Fig. 5. Grain size distribution of the membranes sintered at different temperatures.

at $1000^{\circ} \mathrm{C}, 1050^{\circ} \mathrm{C}$ and $1100^{\circ} \mathrm{C}$, respectively. The porosity determined by image analysis showed a higher value than the porosity obtained by measured density (Table 1 ). The difference could be due to the threshold values set during the image analysis. Fig. 5 shows the grain size distributions within each sample, determined from the EBSD imaging.

In all three samples the grains are randomly oriented, with values of the texture index, $J$, of $1.17\left(1000^{\circ} \mathrm{C}\right), 1.85\left(1050^{\circ} \mathrm{C}\right)$ and 1.21 $\left(1100^{\circ} \mathrm{C}\right)$ for the $(100)$ poles (Fig. 6$)$. The grain boundary misorientation angle distributions follow the expected curves for a random texture in a cubic material (Fig. 7).

The fractions of special CSL boundaries (Fig. 8) are close to the distribution calculated for a random texture [33], i.e. they confirm the lattice preferred orientations (LPO) results, but are slightly higher than expected, although this may be due to parameters used in applying the Brandon criterion [42], which was originally derived to accommodate the effects of tilting at grain boundaries due to dislocation arrays. These microstructural data suggest that the effect of changing the sintering temperature has merely been to adjust the grain size. There is no evidence for changes in texture, or grain boundary structure distribution that might affect permeation rate. The lack of a discernable texture also means that a random distribution of crystal surfaces will be presented at the surface of the membrane.

Fig. 9 depicts the oxygen permeation flux of the BSCF membranes sintered at 1000,1050 and $1100^{\circ} \mathrm{C}$ for $2 \mathrm{~h}$ as a function of the temperature. The error bars correspond to the standard error calculated from the standard deviation of the experimental data. The oxygen permeation fluxes through the membranes are identical within the error margins of the measurement. Our values for the oxygen permeation fluxes at $950^{\circ} \mathrm{C}$ and $850^{\circ} \mathrm{C}$ are compared with those of other $\mathrm{Ba}_{0.5} \mathrm{Sr}_{0.5} \mathrm{Co}_{0.8} \mathrm{Fe}_{0.2} \mathrm{O}_{3-\delta}$ (BSCF) disk membranes reported in the literatures (Table 2). The apparent activation energy for permeation in the temperature range $800-1000^{\circ} \mathrm{C}$ was found to be $\sim 40 \mathrm{~kJ} / \mathrm{mol}$ for all of the membranes used in this study. This value is consistent with other reported values for bulk diffusion in BSCF membranes, which reported the apparent activation energy between 25 and $45 \mathrm{~kJ} / \mathrm{mol}$ in the temperature range of $800-950^{\circ} \mathrm{C}$ $[11,26,43,44]$.

Fig. 10a shows a secondary electron image of the polished face of the BSCF membranes sintered at $1000^{\circ} \mathrm{C}$ and prepared for $\mathrm{CM}$ microscopy. The surface electrodes and electrical contact probes are visible in the image. Fig. $10 \mathrm{~b}$ is a $\mathrm{CM}$ image of the same area. The image brightness is given by the proportion of absorbed beam current flowing to the top electrode. The bright contrast under the top electrode and the dark contrast under the lower electrode is 

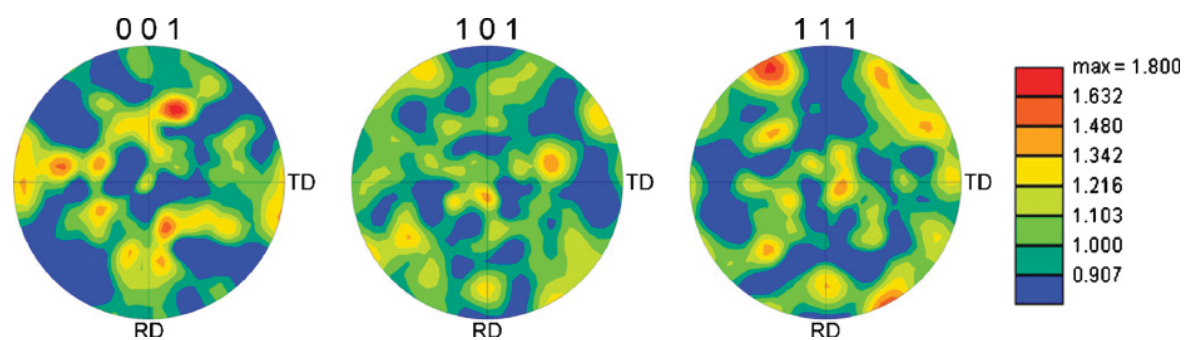

Fig. 6. Pole figures for the (001), (101) and (111) axes of the $1000^{\circ} \mathrm{C}$ sample (max. value is very low). The results for the other two samples are similar (RD: rolling direction and TD: transverse direction).
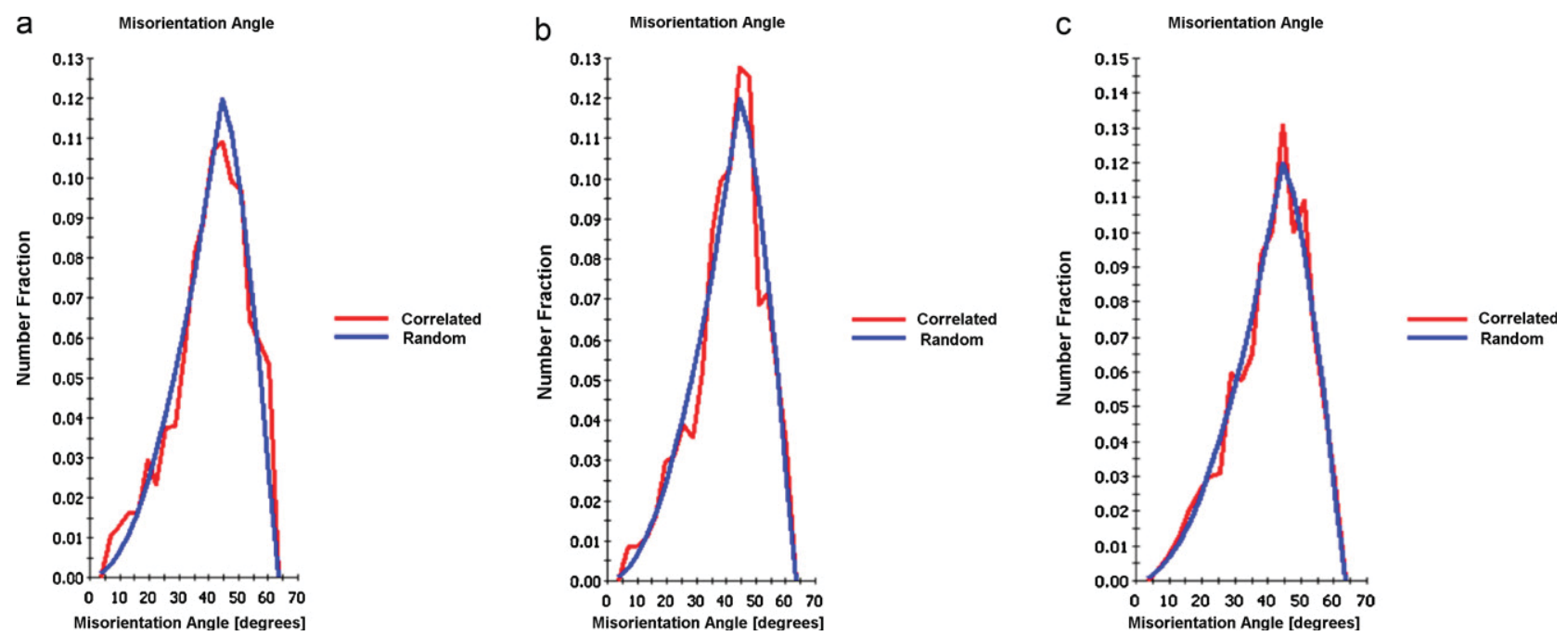

Fig. 7. Grain boundary misorientation angle distributions for (a) $1000^{\circ} \mathrm{C}$, (b) $1050^{\circ} \mathrm{C}$, and (c) $1100^{\circ} \mathrm{C}$. The blue curve is the distribution calculated for a cubic symmetry sample with random texture. (For interpretation of the references to color in this figure legend, the reader is referred to the web version of the article.)

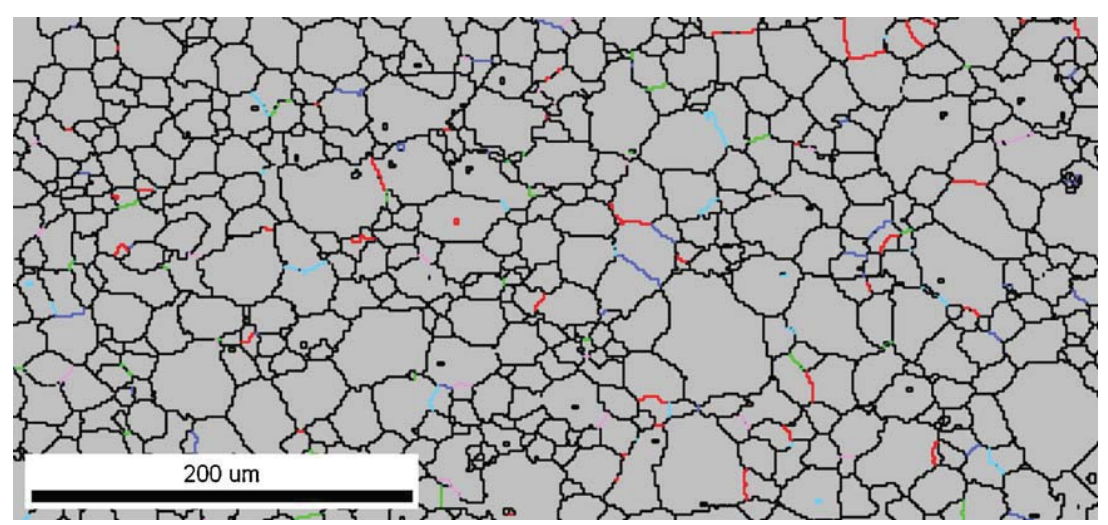

Fig. 8. Grain boundary map for $1050^{\circ} \mathrm{C}$ sample. The colored boundaries correspond to CSL boundaries with $\Sigma=3$ (dark blue), 5 (light blue), 7 (light green), $\geq 9$ (red). (For interpretation of the references to color in this figure legend, the reader is referred to the web version of the article.)

caused by an electron beam induced current (EBIC) arising from the partial Schottky nature of the gold contacts on the sample surface. Between the electrodes, the image has a uniform grey gradient with no microstructural detail. The graph in Fig. 10c shows that the variation in CM current with beam position between the electrodes is linear and since any sudden local change in resistivity would distort the uniform variation of CM current with beam position. This indicates that the sample resistivity is uniform on the scale of the beam excitation volume within this area. The injection of beam electrons changed the resistance between the electrodes by less than $1 \%$ and so the sample free-carrier concentration was not significantly altered by the measurement. It is therefore concluded that the electronic conductivity of the grains and grain boundaries in this region are similar.

It is important for the membranes to remain stable under the operating conditions and to show no degradation in oxygen permeation. Fig. 11 shows the time dependence of the oxygen permeation flux for the BSCF membrane sintered at $1000^{\circ} \mathrm{C} / 2 \mathrm{~h}$. It was found that the permeation flux was nearly constant at $900^{\circ} \mathrm{C}$ after an operation time of more than $50 \mathrm{~h}$, whereas oxygen per- 


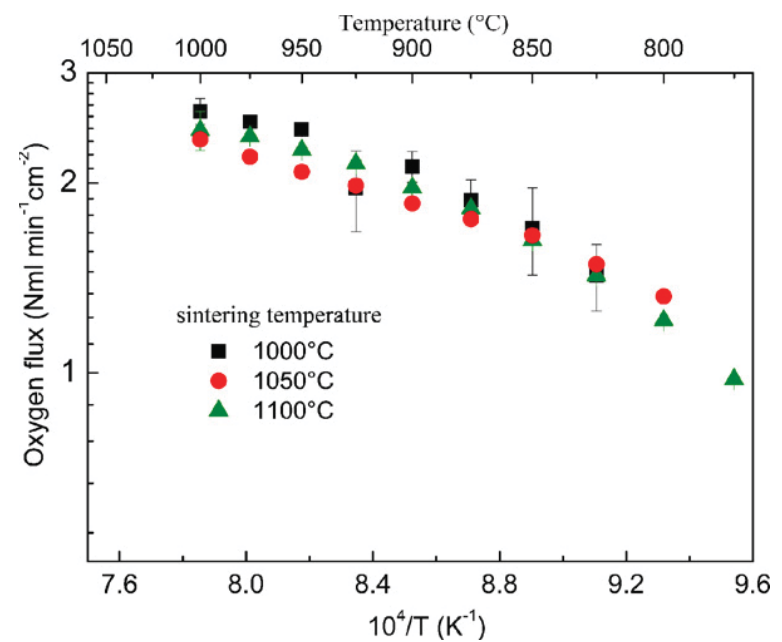

Fig. 9. Temperature dependence of oxygen permeation flux through the different BSCF membranes sintered at $1000^{\circ} \mathrm{C}, 1050^{\circ} \mathrm{C}$ and $1100^{\circ} \mathrm{C}$ for $2 \mathrm{~h}$, air flow rate $=350 \mathrm{Nml} / \mathrm{min}$ and sweep flow rate $100 \mathrm{Nml} / \mathrm{min}$. The data are average values and the error bars correspond to standard error.

meation flux declined after a relatively short time $(20 \mathrm{~h})$ at $825^{\circ} \mathrm{C}$. This difference in behavior with temperature may be attributable to a decrease in the concentration of mobile oxygen vacancy in the lattice owing to changes in the oxidation state of B cations, in which, the structure gives a Goldschmidt tolerance factor higher than one $[3,45]$. Another reason is the hexagonal-cubic phase transition that occurs in BSCF at moderate temperatures [11,13]
Table 2

Comparison of the oxygen permeation fluxes through the $\mathrm{Ba}_{0.5} \mathrm{Sr}_{0.5} \mathrm{Co}_{0.8} \mathrm{Fe}_{0.2} \mathrm{O}_{3-\delta}$ (BSCF) disk-type membranes.

\begin{tabular}{llll}
\hline $\begin{array}{l}\text { Temperature } \\
\left({ }^{\circ} \mathrm{C}\right)\end{array}$ & $\begin{array}{l}\text { Thickness } \\
(\mathrm{mm})\end{array}$ & $\begin{array}{l}\mathrm{O}_{2} \text { flux } \\
\left(\mathrm{ml} / \mathrm{cm}^{2} \mathrm{~min}\right)\end{array}$ & References \\
\hline 950 & 1.50 & 1.60 & {$[1]$} \\
950 & 1.80 & 1.40 & {$[11]$} \\
850 & $1-2$ & 2.01 & {$[12]$} \\
950 & 0.60 & 2.43 & Present work \\
850 & 0.60 & 1.70 & Present $^{\mathrm{a}}$ wrk $^{\mathrm{a}}$ \\
\hline \multicolumn{2}{l}{ a } & \multicolumn{3}{l}{}
\end{tabular}

and this phase transformation would be ordered the oxygen vacancies, whose are almost non-oxygen permeable [9].

\section{Discussion}

The EBSD data show that all three samples have close to random textures with similar grain boundary structure distributions. The only microstructural parameters that change are grain size and porosity: porosity only slightly. Within the accuracy of our experiment, changes in grain size in the range 3-18 $\mu \mathrm{m}$ did not affect the oxygen flux at temperatures in the range $800-1000^{\circ} \mathrm{C}$.

Wang et al. [13] reported a positive, albeit weak, correlation between flux and grain size, in the range $30-140 \mu \mathrm{m}$, which is larger than used in this study. Similar observations were made by Gao et al. [46]. However, these samples had very low densities, ranging from 69 to $85 \%$ of the theoretical BSCF density. A much stronger correlation was observed by Arnold et al. [24], but in this case the grain size (14-17 $\mu \mathrm{m}$ ) was controlled by the amount of BN (boron

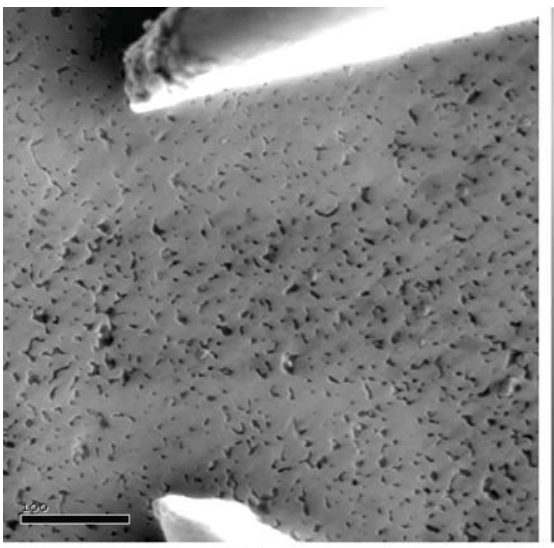

(a)

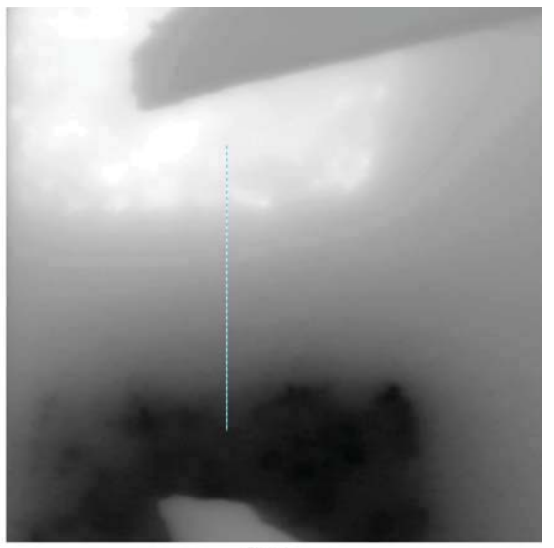

(b)

\section{Line Profile}

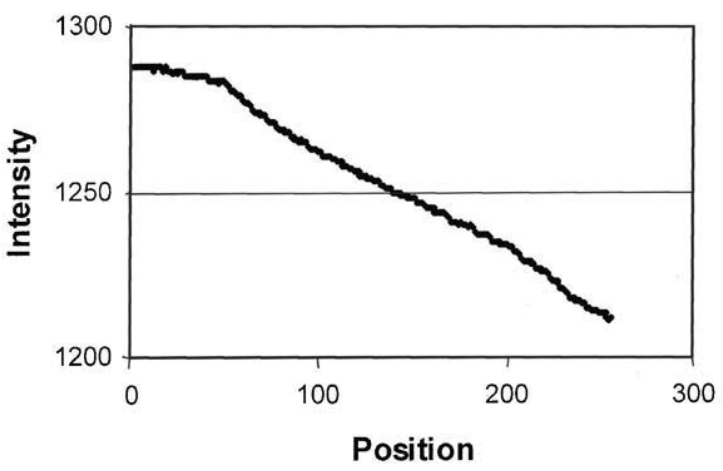

(c)

Fig. 10. (a) Secondary electron image of the polished face of the BSCF, (b) CM image, and (c) variation in CM current with beam position. 


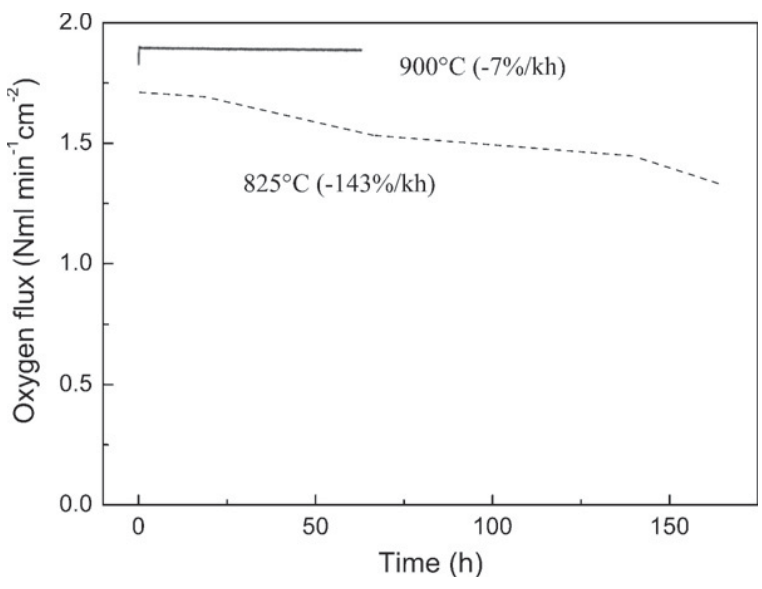

Fig. 11. Oxygen permeation flux through the BSCF membrane as s function of time at 825 and $900^{\circ} \mathrm{C}$ for membrane sintered at $1000^{\circ} \mathrm{C} / 2 \mathrm{~h}$.

nitride) that was added to the powder. Increasing the concentration of BN, which oxidized and melted during sintering, reduced both the grain size and the oxygen permeability. The authors claim, that there is no $\mathrm{B}_{2} \mathrm{O}_{3}$ or related phase along the grain boundaries, but they give no indication about where the $\mathrm{B}_{2} \mathrm{O}_{3}$ is located in the microstructure. Tan et al. [18] also observed an increase in permeability with increasing grain size ( 0.1 and $0.5 \mu \mathrm{m}$ on the surface). However, powders with different synthesis methods were used for preparing the membranes and therefore slight variations in composition might influence the flux performance of the membranes. In contrast to all the above examples, Bouwmeester [23] reported a decrease in flux with increasing grain size and Baumann et al. [26] reported an inverse but very weak relationship between grain size and the oxygen permeation flux for BSCF.

In other related perovskite systems a general explanation about the effect of membrane grain size on the oxygen permeation flux cannot be found. While in the $\mathrm{LaCoO}_{3-\delta}, \mathrm{La}_{0.3} \mathrm{Sr}_{0.7} \mathrm{CoO}_{3-\delta}$ and $\mathrm{La}_{0.6} \mathrm{Sr}_{0.4} \mathrm{Co}_{0.2} \mathrm{Fe}_{0.8} \mathrm{O}_{3-\delta}$ systems oxygen permeation flux increases with increasing grain size [47-49], the opposite is observed for the $\mathrm{La}_{0.5} \mathrm{Sr}_{0.5} \mathrm{FeO}_{3-\delta}, \mathrm{La}_{0.6} \mathrm{Sr}_{0.4} \mathrm{Fe}_{0.9} \mathrm{Ga}_{0.1} \mathrm{O}_{3-\delta}$ and $\mathrm{La}_{0.1} \mathrm{Sr}_{0.9} \mathrm{Co}_{0.9} \mathrm{Fe}_{0.1} \mathrm{O}_{3-\delta}$ systems $[20,50,51]$. Slower ionic transport at the grain boundary is well known as the grain boundary blocking effect, which is mainly attributed to impurities, solute segregation, or second phase at the grain boundary: even in high purity materials [20,52-54]. Thus, the smaller grain size and consequent higher area of grain boundary lead to lower total conductivities.

In the present work, we have established that for a random texture the oxygen permeation flux in BSCF is not dependent on grain size and/or grain boundary volume, and have found no evidence for a grain boundary blocking effect in BSCF. The independence of the electronic conductivity from intervening grain boundary was confirmed by $\mathrm{CM}$ measurements.

\section{Conclusion}

BSCF membranes, $0.6 \mathrm{~mm}$ in thickness, were fabricated by the warm pressing method using thermoplastic processing. Different grain sizes were obtained by sintering the samples at $1000^{\circ} \mathrm{C}$, $1050^{\circ} \mathrm{C}$ and $1100^{\circ} \mathrm{C}$ for $2 \mathrm{~h}$. A density of the $96 \%$ was achieved for the membrane sintered at $1000^{\circ} \mathrm{C}$ and $98 \%$ for $1100^{\circ} \mathrm{C}$. An average grain size of $3.23 \mu \mathrm{m}$ for fine grained membrane and $18.25 \mu \mathrm{m}$ for coarse grained membrane were determined. Permeation flux measurements showed no difference in performance for membranes sintered at different sintering temperatures. EBSD revealed that there is no lattice preferred orientation as indicated by the values of the texture index $J$, for all three membranes. CM method also showed that the electronic conductivity of the grains and grain boundaries in this region are similar. The stability of the membranes associated with oxygen permeability was investigated and results showed that at temperatures lower than $900^{\circ} \mathrm{C}$ the oxygen permeation flux declined with time.

\section{Acknowledgements}

The authors would like to acknowledge the financial contribution provided by Swiss Electric Research and the Competence Center for Energy \& Mobility (CCEM) in Switzerland. The authors also would like to thank Mr. Christoph Neururer at Université de Fribourg for the EBSD measurements.

\section{References}

[1] Z. Shao, G. Xiong, H. Dong, W. Yang, L. Lin, Synthesis, oxygen permeation study and membrane performance of a $\mathrm{Ba}_{0.5} \mathrm{Sr}_{0.5} \mathrm{Co}_{0.8} \mathrm{Fe}_{02} \mathrm{O}_{3}$-deltal oxygenpermeable dense ceramic reactor for partial oxidation of methane to syngas, Separation and Purification Technology 25 (2001) 97-116.

[2] M.D. Mat, X. Liu, Z. Zhu, B. Zhu, Development of cathodes for methanol and ethanol fuelled low temperature $\left(300-600^{\circ} \mathrm{C}\right)$ solid oxide fuel cells, International Journal of Hydrogen Energy 32 (2007) 796-801.

[3] S. Svarcová, K. Wiik, J. Tolchard, H.J.M. Bouwmeester, T. Grande, Structural

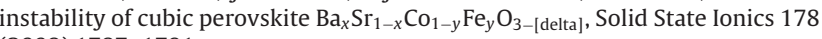
(2008) 1787-1791.

[4] Z. Chen, R. Ran, Z. Shao, H. Yu, J.C.D.d. Costa, S. Liu, Further performance improvement of $\mathrm{Ba}_{0.5} \mathrm{Sr}_{0.5} \mathrm{Co}_{0.8} \mathrm{Fe}_{0.2} \mathrm{O}_{3 \text { - [deltal }}$ perovskite membranes for air separation, Ceramics International 35 (2009) 2455-2461.

[5] Y. Teraoka, H.M. Zhang, S. Furukawa, N. Yamazoe, Oxygen permeation through perovskite-type oxides, Chemistry Letters 14 (1985) 1743-1746.

[6] Y. Teraoka, H.M. Zhang, K. Okamoto, N. Yamazoe, Mixed ionic-electronic conductivity of $\mathrm{La}_{1-x} \mathrm{Sr}_{x} \mathrm{Co}_{1-y} \mathrm{Fe}_{y} \mathrm{O}_{3-\delta}$ perovskite-type oxides, Materials Research Bulletin 23 (1988) 51-58.

[7] H. Kruidhof, H.J.M. Bouwmeester, R.H.E.v. Doorn, A.J. Burggraaf, Influence of order-disorder transitions on oxygen permeability through selected nonstoichiometric perovskite-type oxides, Solid State Ionics 63-65 (1993) 816-822.

[8] V.V. Kharton, A.A. Yaremchenko, E.N. Naumovich, Research on the electrochemistry of oxygen ion conductors in the former Soviet Union. II. Perovskite-related oxides, Journal of Solid State Electrochemistry 3 (1999) 303-326.

[9] T. Nagai, W. Ito, T. Sakon, Relationship between cation substitution and stability

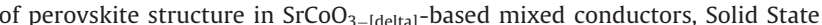
Ionics 177 (2007) 3433-3444.

[10] Z. Rui, J. Ding, Y. Li, Y.S. Lin, $\mathrm{SrCo}_{0.8} \mathrm{Fe}_{0.2} \mathrm{O}_{3 \text {-[delta] }}$ sorbent for high-temperature production of oxygen-enriched carbon dioxide stream, Fuel 89 (2010) $1429-1434$.

[11] Z. Shao, W. Yang, Y. Cong, H. Dong, J. Tong, G. Xiong, Investigation of the permeation behavior and stability of a $\mathrm{Ba}_{0.5} \mathrm{Sr}_{0.5} \mathrm{Co}_{0.8} \mathrm{Fe}_{0.2} \mathrm{O}_{3 \text {-[delta] }}$ oxygen membrane, Journal of Membrane Science 172 (2000) 177-188.

[12] H. Lu, J. Tong, Y. Cong, W. Yang, Partial oxidation of methane in $\mathrm{Ba}_{0.5} \mathrm{Sr}_{0.5} \mathrm{Co}_{0.8} \mathrm{Fe}_{0.2} \mathrm{O}_{3-\text { [delta] }}$ membrane reactor at high pressures, Catalysis Today 104 (2005) 154-159.

[13] H. Wang, C. Tablet, A. Feldhoff, J. Caro, Investigation of phase structure, sintering, and permeability of perovskite-type $\mathrm{Ba}_{0.5} \mathrm{Sr}_{0.5} \mathrm{Co}_{0.8} \mathrm{Fe}_{0.2} \mathrm{O}_{3 \text {-[delta] }}$ membranes, Journal of Membrane Science 262 (2005) 20-26.

[14] J.F. Vente, S. McIntosh, W.G. Haije, H.J.M. Bouwmeester, Properties and performance of $\mathrm{Ba}_{x} \mathrm{Sr}_{1-\chi} \mathrm{Co}_{0.8} \mathrm{Fe}_{0.2} \mathrm{O}_{3-\delta}$ materials for oxygen transport membranes, Journal of Solid State Electrochemistry 10 (2006) 581-588.

[15] P. Zeng, Z. Chen, W. Zhou, H. Gu, Z. Shao, S. Liu, Re-evaluation of $\mathrm{Ba}_{0.5} \mathrm{Sr}_{0.5} \mathrm{Co}_{0.8} \mathrm{Fe}_{0.2} \mathrm{O}_{3 \text {-[delta] }}$ perovskite as oxygen semi-permeable membrane, Journal of Membrane Science 291 (2007) 148-156.

[16] K.Zhang, Y.L. Yang, D. Ponnusamy, A.J. Jacobson, K. Salama, Effect of microstructure on oxygen permeation in $\mathrm{SrCo}_{0.8} \mathrm{Fe}_{0.2} \mathrm{O}_{3-\delta}$, Journal of Materials Science 34 (1999) 1367-1372.

[17] V.V. Kharton, E.N. Naumovich, A.V. Kovalevsky, A.P. Viskup, F.M. Figueiredo, I.A. Bashmakov, F.M.B. Marques, Mixed electronic and ionic conductivity of $\mathrm{LaCo}(\mathrm{M}) \mathrm{O}_{3}(\mathrm{M}=\mathrm{Ga}, \mathrm{Cr}$, Fe or Ni): IV. Effect of preparation method on oxygen transport in $\mathrm{LaCoO}_{3-[d e l t a]}$, Solid State Ionics 138 (2000) 135-148.

[18] L. Tan, X. Gu, L. Yang, W. Jin, L. Zhang, N. Xu, Influence of powder synthesis methods on microstructure and oxygen permeation performance of $\mathrm{Ba}_{0.5} \mathrm{Sr}_{0.5} \mathrm{Co}_{0.8} \mathrm{Fe}_{0.2} \mathrm{O}_{3 \text {-[delta] }}$ perovskite-type membranes, Journal of Membrane Science 212 (2003) 157-165.

[19] S. Diethelm, J.V. Herle, J. Sfeir, P. Buffat, Influence of microstructure on oxygen transport in perovskite type membranes, British Ceramic Transactions 103 (2004) 147-152.

[20] S. Diethelm, J.Van herle, J. Sfeir, P. Buffat, Correlation between oxygen transport

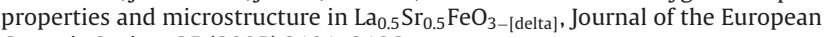
Ceramic Society 25 (2005) 2191-2196.

[21] A.L. Shaula, R.O. Fuentes, F.M. Figueiredo, V.V. Kharton, F.M.B. Marques, J.R. Frade, Grain size effects on oxygen permeation in submicrometric 
$\mathrm{CaTi}_{0.8} \mathrm{Fe}_{0.2} \mathrm{O}_{3-\text { [delta] }}$ ceramics obtained by mechanical activation, Journal of the European Ceramic Society 25 (2005) 2613-2616.

[22] M. Arnold, H. Wang, A. Feldhoff, Influence of $\mathrm{CO}_{2}$ on the oxygen permeation performance and the microstructure of perovskite-type $\left(\mathrm{Ba}_{0.5} \mathrm{Sr}_{0.5}\right)\left(\mathrm{Co}_{0.8} \mathrm{Fe}_{0.2}\right) \mathrm{O}_{3-[\text { delta] }}$ membranes, Journal of Membrane Science 293 (2007) 44-52.

[23] H.J.M. Bouwmeester, Mixed ionic-electronic conducting membranes for oxygen separation, in: 9 Jülicher Werkstoffsymposium, Jülich, Germany, 2007.

[24] M. Arnold, J. Martynczuk, K. Efimov, H. Wang, A. Feldhoff, Grain boundaries as barrier for oxygen transport in perovskite-type membranes, Journal of Membrane Science 316 (2008) 137-144.

[25] M. Zwick, E.M. Pfaff, Microstructure optimization of $\mathrm{Ba}_{0.5} \mathrm{Sr}_{0.5} \mathrm{Co}_{0.8} \mathrm{Fe}_{0.2} \mathrm{O}_{3-}$ perovskite for OTM reactors, in: 32nd International Conference on Advanced Ceramics and Composites, Daytona Beach, Florida, USA, 2008.

[26] S. Baumann, F. Schulze-Küppers, S. Roitsch, M. Betz, M. Zwick, E.M. Pfaff, W.A. Meulenberg, J. Mayer, D. Stöver, Influence of sintering conditions on microstructure and oxygen permeation of $\mathrm{Ba}_{0.5} \mathrm{Sr}_{0.5} \mathrm{Co}_{0.8} \mathrm{Fe}_{0.2} \mathrm{O}_{3 \text {-[delta] }}$ (BSCF) oxygen transport membranes, Journal of Membrane Science 359 (2010) 102-109.

[27] F. Clemens, T. Graule, Thin wall ceramic tubes by extrusion of thermoplastic- $\mathrm{ZrO}_{2}$ compounds Key Engineering Materials, vol. 206-213, Trans Tech Publications, Zurich, 2002, pp. 425-428.

[28] D.J. Prior, A.P. Boyle, F. Brenker, M.C. Cheadle, D. Austin, G. Lopez, L. Peruzzo, G.J Potts, S. Reddy, R. Spiess, N.E. Timms, P. Trimby, J. Wheeler, L. Zetterström, The application of electron backscatter diffraction and orientation contrast imaging in the SEM to textural problems in rocks, American Mineralogist 84 (1999) 1741-1759.

[29] F.J. Humphreys, Review grain and subgrain characterisation by electron backscatter diffraction, Journal of Materials Science 36 (2001) 3833-3854.

[30] J. Cho, C.M. Wang, H.M. Chan, J.M. Rickman, M.P. Harmer, A study of grainboundary structure in rare-earth doped aluminas using an EBSD technique, Journal of Materials Science 37 (2002) 59-64.

[31] P.A. Stadelmann, EMS - a software package for electron diffraction analysis and HREM image simulation in materials science, Ultramicroscopy 21 (1987) 131-145.

[32] H.J. Bunge, Texture Analysis in Materials Science, Butterworths, London, 1982

[33] P. Vonlanthen, B. Grobety, CSL grain boundary distribution in alumina and zirconia ceramics, Ceramics International 34 (2008) 1459-1472.

[34] P.H. Pumphrey, K.M. Bowkett, Axis/angle pair description of coincidence site lattice grain boundaries, Scripta Metallurgica 5 (1971) 365-369.

[35] S. Diethelm, J. Sfeir, F. Clemens, J. Van herle, D. Favrat, Planar and tubular perovskite-type membrane reactors for the partial oxidation of methane to syngas, Journal of Solid State Electrochemistry 8 (2004) 611617.

[36] W. Ehrenberg, D.J. Gibbons, Electron Bombardment Induced Conductivity and its Applications, Academic Press, New York, 1981.

[37] C.A. Smith, C.R. Bagnell, E.I. Cole Jr., F.A. DiBianca, D.G. Johnson, W.V Oxford, R.H. Propst, Resistive contrast imaging: a new SEM mode for failure analysis, IEEE Transactions on Electron Devices ED-33 (1986) 282285.
[38] J. Palm, H. Alexander, Direct measurement of the local diffusion length grainboundaries by ebic without a schottky contact, Journal of Physics IV 1 (1991) 101-106.

[39] D.B. Holt, Local grain boundary property measurements, Solid State Phenomena 37-38 (1994) 171-182.

[40] D.C. Halls, C. Leach, Processing-induced resistive barriers in $\mathrm{ZnO}$ varistor material, Journal of Materials Science 30 (1995) 2733-2737.

[41] J.D. Russell, D.C. Halls, C. Leach, Direct observation of grain boundary Schottky barrier behaviour in zinc oxide varistor material, Journal of Materials Science Letters 14 (1995) 676-678.

[42] D.G. Brandon, The structure of high-angle grain boundaries, Acta Metallurgica 14 (1966) 1479-1484.

[43] Z. Shao, S.M. Haile, A high-performance cathode for the next generation of solid-oxide fuel cells, Nature 431 (2004) 170-173.

[44] J.S. Yoon, M.Y. Yoon, E.J. Lee, J.-W. Moon, H.J. Hwang, Influence of $\mathrm{Ce}_{0.9} \mathrm{Gd}_{0.1} \mathrm{O}_{2 \text {-[delta] }}$ particles on microstructure and oxygen permeability of $\mathrm{Ba}_{0.5} \mathrm{Sr}_{0.5} \mathrm{Co}_{0.8} \mathrm{Fe}_{0.2} \mathrm{O}_{3-\text { Idelta] }}$ composite membrane, Solid State Ionics 181 (2010) 1387-1393.

[45] K. Efimov, Q. Xu, A. Feldhoff, Transmission electron microscopy study of $\mathrm{Ba}_{0.5} \mathrm{Sr}_{0.5} \mathrm{Co}_{0.8} \mathrm{Fe}_{0.2} \mathrm{O}_{3-\delta}$ perovskite decomposition at intermediate temperatures, Chemistry of Materials 22 (2010) 5866-5875.

[46] D. Gao, J. Zhao, W. Zhou, R. Ran, Z. Shao, Influence of high-energy ball milling of the starting powder on the sintering; microstructure and oxygen permeability of $\mathrm{Ba}_{0.5} \mathrm{Sr}_{0.5} \mathrm{Co}_{0.5} \mathrm{Fe}_{0.5} \mathrm{O}_{3-\text { [delta] }}$ membranes, Journal of Membrane Science 366 (2011) 203-211.

[47] V.V. Kharton, F.M. Figueiredo, A.V Kovalevsky, A.P. Viskup, E. N. Naumovich, A.A Yaremchenko, I.A. Bashmakov, F.M.B. Marques, Processing, microstructure and properties of $\mathrm{LaCoO}_{3-[\text { delta] }}$ ceramics, Journal of the European Ceramic Society 21 (2001) 2301-2309.

[48] V.V. Kharton, A.V. Kovalevsky, A.A. Yaremchenko, F.M. Figueiredo, E.N. Naumovich, A.L Shaulo, F.M.B. Marques, Surface modification of $\mathrm{La}_{0.3} \mathrm{Sr}_{0.7} \mathrm{CoO}_{3-[\text { delta] }}$ ceramic membranes, Journal of Membrane Science 195 (2002) 277-287.

[49] P. Zeng, R. Ran, Z. Chen, H. Gu, Z. Shao, J.C.D. da Costa, S. Liu, Significant effects of sintering temperature on the performance of $\mathrm{La}_{06} \mathrm{Sr}_{0.4} \mathrm{Co}_{0.2} \mathrm{Fe}_{0.8} \mathrm{O}_{3-\text { deltal }}$ oxygen selective membranes, Journal of Membrane Science 302 (2007) 171-179.

[50] G. Etchegoyen, T. Chartier, A. Julian, P. Del-Gallo, Microstructure and oxygen permeability of $\mathrm{La}_{0.6} \mathrm{Sr}_{0.4} \mathrm{Fe}_{0.9} \mathrm{Ga}_{0.1} \mathrm{O}_{3-\delta}$ membrane containing magnesia as dispersed second phase particles, Journal of Membrane Science 268 (2006) 86-95.

[51] H. Kusaba, Y. Shibata, K. Sasaki, Y. Teraoka, Surface effect on oxygen permeation through dense membrane of mixed-conductive LSCF perovskite-type oxide, Solid State Ionics 177 (2006) 2249-2253.

[52] S.P.S. Badwal, Zirconia-based solid electrolytes: microstructure, stability and ionic conductivity, Solid State Ionics 52 (1992) 23-32.

[53] X. Guo, J. Fleig, J. Maier, Separation of electronic and ionic contributions to the grain boundary conductivity in acceptor-doped SrTiO[sub 3], Journal of The Electrochemical Society 148 (2001) J50-J53.

[54] J. Maier, Transport in electroceramics: micro- and nano-structural aspects, Journal of the European Ceramic Society 24 (2004) 1251-1257. 